\title{
SIMULATION STUDIES INTO QUAYSIDE TRANSPORT AND STORAGE YARD OPERATIONS IN CONTAINER TERMINALS
}

\author{
Mariusz Deja \\ Michał Dobrzyński \\ Mieczysław S.Siemiątkowski \\ Aleksandra Wiśniewska \\ Gdansk University of Technology, \\ Mechanical Engineering Faculty, Dept. of Manufacturing Engineering and Automation, Gdansk, Poland
}

\begin{abstract}
The focus of the paper is in quayside transport and storage yard operations in container terminals. Relevant algorithms have been applied and a simulation model adopted. Evaluative criteria chosen for that model were: the total time of ship unloading and the truck utilization level. Recommendations for unloading in berth and yard areas were analysed in three different case studies. Results of simulations and deterministic model based analyses are included.
\end{abstract}

Keywords: container terminals, mechanical handling, simulation modelling, quantitative analysis.

\section{INTRODUCTION}

The container terminal enables efficient container flow between ships and inland transport means. Containers transported from ships to trucks or trains are called import containers, while those taking the reverse route bear the name of export containers [3]. Transshipment containers are transported between ships. In all cases, the containers are delivered to the terminal yard and stored for few days before being transported either to the berth for ship loading (export, transshipment), or by inland transport means (import) [10]. The yard planning involves allocation of storage spaces for import, export and transshipment containers [13, 17]. The yard is divided into several blocks, and each block consists of several bays. Each bay in the block has the same number of stacks. One of most common problems in the terminal transportation system is the container relocation problem (CRP) which has to be solved when containers, piled up in stacks, need to be transported to a ship or to trucks in a predefined sequence. Forster and Bortfeldt propose an effective tree search procedure for the CRP [3].

As assumed in [13], container terminals perform various handling operations by utilizing such resources as quay cranes (QCs), storage yards (SYs), yard cranes (YCs), travelling areas (TAs), and transporters (TRs). The travelling area represents a traffic zone or a set of transfers for trucks and transporters, including internal moving vehicles (IMVs) or automated guided vehicles (AGV). Xin et al. [14] propose a methodology to generate collision-free trajectories of free-ranging AGVs in automated container terminals, while minimizing the makespan of the whole container handling system. Two most important performance measures in the container terminal are the turnaround time of ships, trucks, and trains in the terminal. Proper yard planning with adequate CRP solving are crucial for minimizing the turnaround time. This paper addresses mostly terminal operation activities related to its landside, such as outbound container transportation with IMVs and, consequently, their stowage into the assigned storage yards. Vessels are unloaded by one or more quay cranes (QCs) according to the unloading plan. Containers are then relayed to transfer vehicles (IMVs or AGVs), which transport them to the storage yard where they are temporarily stored by yard cranes (YCs). Depending on their destination, containers may be transshipped to another vessel, or dispatched, via terminal gates, for transport by trucks or trains after being inspected. The objective of this paper is minimizing the turnaround time of the vessel unloading at a definite berth location with the utilisation of the required number of IMVs. An efficient operational plan in container terminals requires a large number of factors to be considered 
for decision-making [13]. The simulation of vessel unloading with available IMVs to a chosen storage yards can help to make the proper decision concerning the storage yard choice, to minimize the turnaround time of vessel unloading and to utilise the minimum number of IMVs required to unload the vessel without breaks $[15,16]$.

\section{LITERATURE OVERVIEW}

Problems with seaport container terminal planning and operation have attracted a great deal of research attention, and there is abundant literature available on this subject. However, despite a significant progress in this area, it is particularly the issues associated with load transportation and storage yard operation which still remain to be fully solved. Much of current effort is aimed at the container relocating problem (CRP) which occurs in container terminals of seaports [3]. Efficacious integration of individual subtasks into the planning and operation task of terminals still remains a problem in engineering practice of container terminals, and thus, it constantly attracts research attention. In general terms, container terminals can be described as open systems of material flow with two external interfaces [9]. These interfaces are: (1) the quayside with loading and unloading of ships, and (2) the landside where containers are loaded and unloaded on/off trucks and trains. Loading and unloading of vehicles for horizontal transport is done by cranes, either quay cranes or gantry cranes $[5,9]$. The frameworks provided for integrating various planning activities in container terminals consider two basic planning problems:

- planning problem in the quayside: berth allocation, ship stowage planning, quay crane scheduling;

- planning problem in the landside: yard storage and stacking planning, yard crane scheduling, vehicle scheduling.

From a logistic point of view, terminals only consist of two components: stocks and transport vehicles. The yard stacks, ships, trains, and trucks belong to the category 'stock' [9]. Problems with yard storage and stacking planning are considered with maximum utilization of the storage space, minimum transport distance from quay to stack and vice versa, and minimum number of unproductive moves [11]. The main constraints in yard storage and stacking planning are maximum stack tiers depending on the stacking equipment and container attributes, such as: size, weight, reefer, dangerous, damaged.

A stowage (or loading) instruction is necessary to define the rules how and where containers have to be stored [1, 2]. Problems with yard crane scheduling refer to minimum waiting time of the truck at the yard and to minimum travelling time of the yard crane in the yard zone. The main constrains in yard crane scheduling are: the process of physical handling of yard cranes and the accessibility of a yard crane in the yard. Problems with vehicle scheduling are also related to the minimisation of the lateness of container deliveries, empty travel distances, and loaded travel times, like in production systems [4].
Quayside problems analysed in the literature are related to the trade-off optimization between the vessel's turnaround time and the number of the used berths and quay cranes. The utilization of berths and quay cranes taking into account random vessel arrivals and some fluctuations in the analysed system is also optimised. Different logistic concepts, decision rules and optimization algorithms have to be compared by simulation before they are implemented into real systems $[6 \div 8]$.

This paper addresses mostly the terminal operation activities related to its landside, such as outbound containers transportation with IMVs and consequently their stowage into the assigned storage yards. The objective is aimed at minimizing the turnaround time of vessel unloading at a definite berth location. In this research, the issues of operative planning of overall logistic processes performed in seaport terminals underwent a comprehensive analysis and resultant evaluation. Following the preliminary assumptions based on the concept of deterministic models, a discrete event simulation approach was applied to system analysis and relevant quantitative evaluation of its operational characteristics was obtained. Three alternative scenarios were neatly considered throughout the presented quantitative study.

\section{PRELIMINARIES AND PROBLEM OVERVIEW}

The founded model assumes that the transport of containers takes place by/within ship - yard's storage area. The ship waiting at quayside for discharge is divided into 2 to 4 sections (berths), depending on the ship's length, Fig. 1. Each section is supported by one Quay Crane moving along the quay and the ship. Transport is done by using IMV trucks. Containers are taken by the crane from the ship and loaded on trucks, which carry the container to a designated location on the yard's storage space using a determined path. There, the container is being received by the yard's crane and is placed in the right/dedicated place on the yard's storage area - bay, Fig. 2. One gantry crane supports two yard's storage areas.

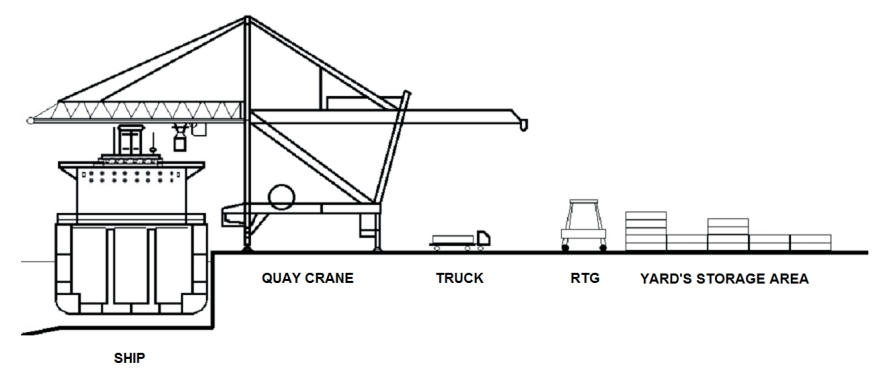

Fig. 1. Loading/unloading operations - general view

In the analysed case the yard's storage area consists of two parts, Fig. 3. The first part has 12 storage fields for both 
conventional and refrigerated containers, while the second area has two fields used for of hazardous load and undersized containers. The storage area is a cube with dimensions of $7 \times 10 \times 5$ (numbers of containers in width $\mathrm{x}$ length $\mathrm{x}$ height). For logistic reasons, the statistical fulfilment of a cube of containers is $80 \%$. This value has resulted from the need to perform manoeuvres of containers. When the container to be loaded on a ship is in one of the lower or middle layers, to access it the gantry needs to make so called relocation operation, i.e. to download and put in free space containers stored on the sought container. The founded model assumes that the use of the fields (operational) is at $60 \%$ due to low load orders' number of storing containers.

IMV trucks move along designated routes between the quay crane and the yard crane (gantry of RTG type). Most often they do it at a speed of up to approx. $30 \mathrm{~km} / \mathrm{h}$, and the assumed model adopted the average truck speed of $20 \mathrm{~km} / \mathrm{h}$.

a)

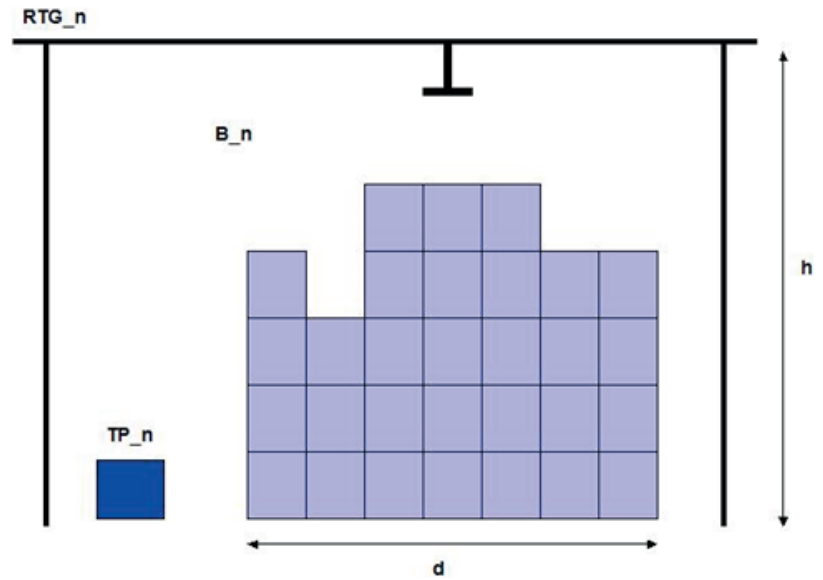

b)

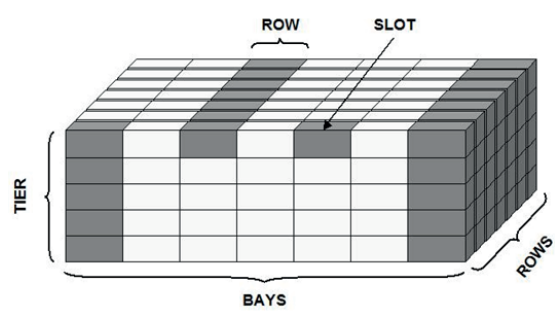

Fig. 2. Yard crane and containers stacked in tiers (a) and in individual block (b)

Containers are the object of loading and unloading operations. They can be of different types and sizes: conventional containers of small size (length 20 ,), conventional containers of large size (length 40'), refrigerated containers (requiring storage oriented to the direction of the location of power connections), containers carrying hazardous loads (requiring usually dedicated fields and sometimes even the space separating them from other containers), and containers with protruding elements, so called POG. It is conventional and refrigerated containers which prevail in logistical practice, while the containers with hazardous loads and projecting parts are generally up to $10 \%$ of the total number of containers transported.

\section{SIMULATION CASE STUDY OF LOAD TRANSPORTATION AND STORAGE SPACE ALLOCATION}

In the simulation project, a model with quayside unloading operations performed in regard to a medium-sized vessel of medium tonnage has been adopted as the illustrative case study. However, it involved carrying containers of different types, including those of 20' and 40' in length, as well as reefer or hazardous goods containers, or oversized ones. The containers within the developed model are available in three categories: A, B and C, correspondingly to their type, i.e. large and small containers (without distinction between conventional or reefer ones), and hazardous load or nonstandard-sized containers. Containers A and B are deposited within the designated storage yard area and divided into a number of blocks (colour blue, block numbers from B1 to B12), while the C-type containers are deposited on a dedicated special blocks (red, B13 and B14), Fig. 3.

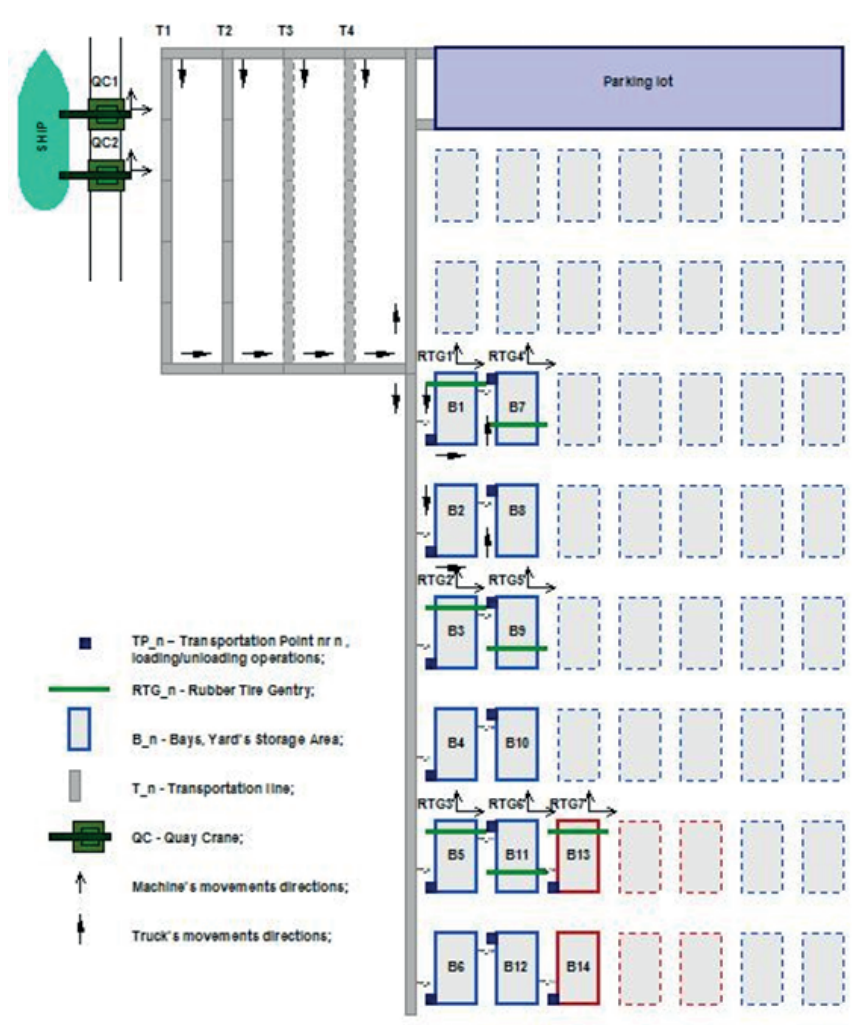

Fig. 3. Layout of the seaport terminal under investigation

In order to find the best design solution, different alternative scenarios were neatly considered throughout the presented quantitative study. Basic attributes for terminal equipment and their operating characteristics used for the simulations are given in Table 1. A simplified flowchart of the container terminal operation of the analysed quayside is presented in Fig. 4. 
Table1. Basic attributes for terminal equipment and their operating characteristics

\begin{tabular}{cc}
\hline $\begin{array}{c}\text { Type of equipment / } \\
\text { parameters }\end{array}$ & Resource characteristic \\
\hline $\begin{array}{c}\text { Number of quay cranes } \\
\text { (QC) }\end{array}$ & 2 \\
$\begin{array}{c}\text { Cycle time of quay crane } \\
\text { (QC) [min] }\end{array}$ & Uniform $(2.0,3.0)$ \\
Number of rubber-tyred \\
gantry cranes (RTG) \\
$\begin{array}{c}\text { Cycle time of rubber-tyred } \\
\text { gantry crane (RTG) [min] } \\
\text { Number of IMV } \\
\text { multipurpose vehicles } \\
\text { IMV speed [m/min] } \\
\text { IMV speed [m/min] }\end{array}$ \\
\hline
\end{tabular}

${ }^{\star}$ for scenario $1 ;{ }^{* *}$ for scenario 2

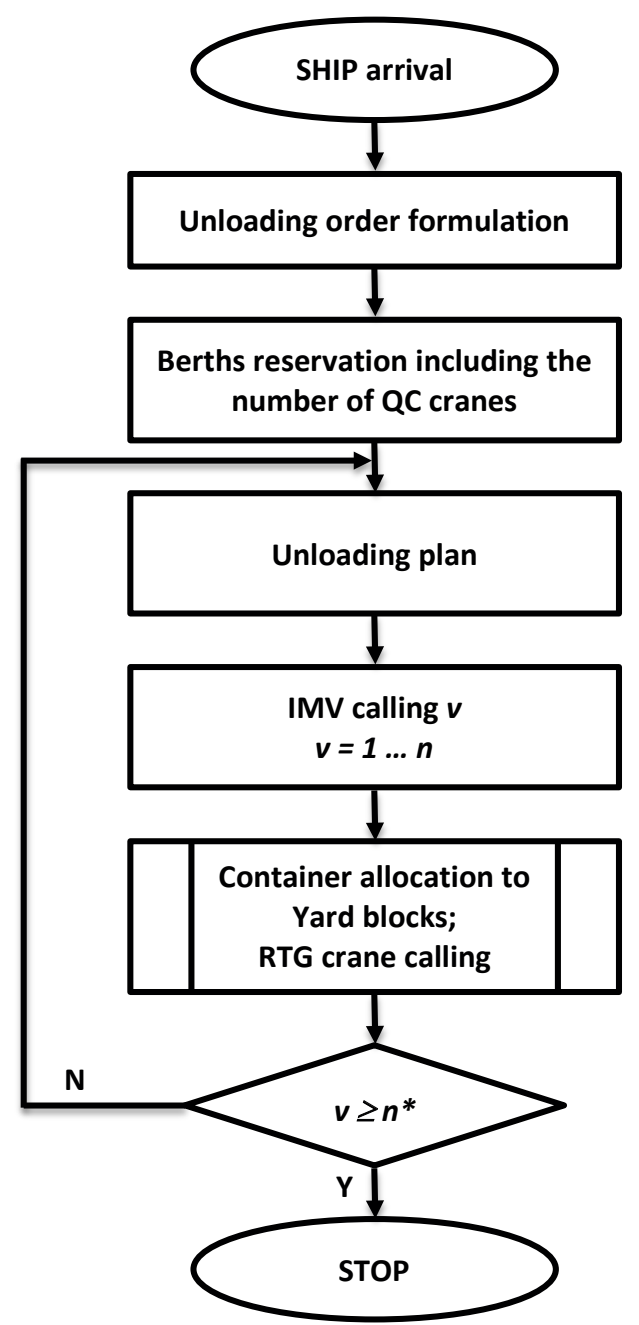

Fig. 4. Simplified flowchart of container terminal operation of the analysed quayside

The detailed unloading plan for a vessel, prepared for $\mathrm{QC1}$ and QC2, is characterised by intermittent inflow of containers of different types: A, B, and C, Fig. 5. The sequences of containers' stowage in the storage area for two analysed scenarios are illustrated by directed graph models with shaded nodes denoting starting block locations, Fig. 6. a)

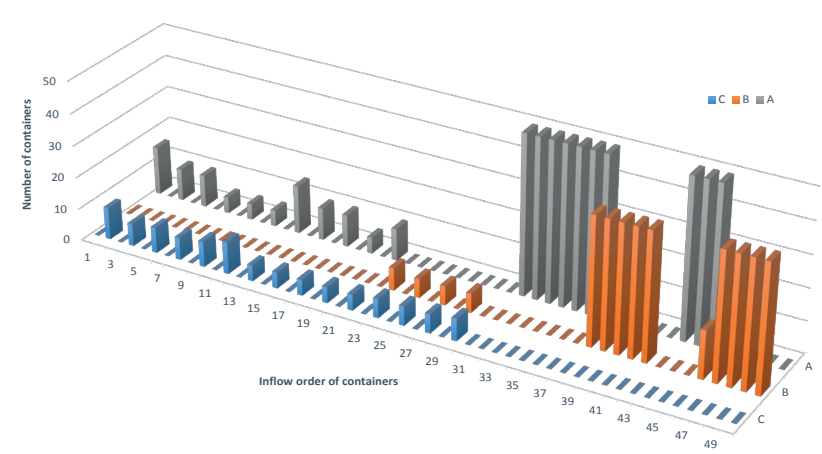

b)

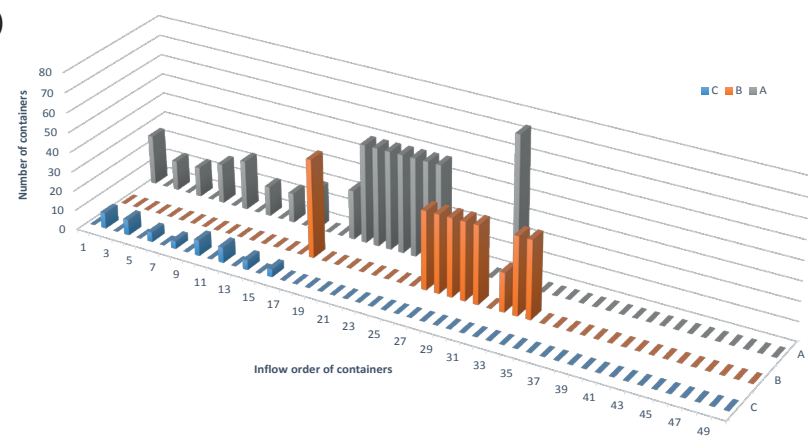

Fig. 5. Input profiles for intermittent inflow of containers by unloading plan for QC1 (a) and QC2 (b), respectively.

The adopted model was analysed in a series of experiments, taking into account the following criteria of quantitative system analysis:

- the total time of unloading a ship with relocation of containers from the ship to definite blocks in the storage yard space,

- the level of utilisation of individual vehicles assumed as the target function.
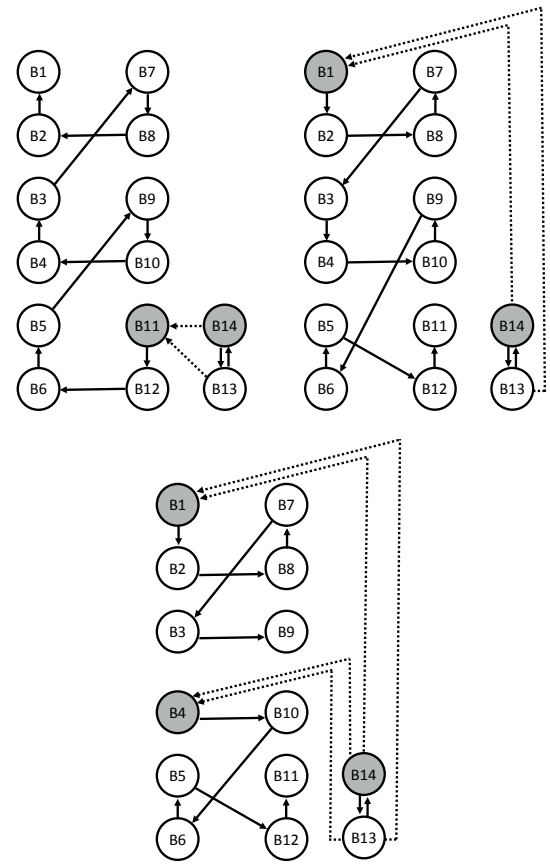

Fig. 6. Directed graph models showing the sequence of containers' stowage in the storage area for Scenario 1 (a) and Scenario 2 (b); shaded nodes denote starting block locations. 
The following assumptions formed the basis for analytical considerations used to obtain starting estimates of system performance, and further on at the stage of simulation modelling:

- number of IMV vehicles equal to the number of fields of storage yard area,

- number of IMV vehicles equal to the number of RTG cranes serving the storage yard area,

- optimum number of vehicles at the shortest ship unloading, and the assumption of continuity of the QC crane working cycle.

In the wake of the above, three adequate cases were consequently adopted within the framework of the simulation analysis, correspondingly with the ascertained number of transport resources operating in the storage yard area.

The transport path in the frame of the definite mesh routing for IMV_n (Vehicle_n) passes through the elements shown in Fig. 3 and requires some identifications:

Parking lot - the route $\left(\mathrm{T} \_n\right)$ - QuayCrane_n - identification of the type of container $(A, B, C)$ - truck_n - Yard Storage Space (TP_n) - unloading RTG_n - path transport T_n - parking lot.

The simulation investigations of process alternatives have been carried out in the environment of Witness [12], the interactive software package, with the use of programmable models to map real operating characteristics of the seaport container terminal.

\section{SIMULATION RESULTS AND RELATED DISCUSSION}

Various data have been derived from experiments, and among other those related to resource utilisation during stowage of containers within the assigned storage area and stacking the unit loads in tiers within destination blocks.

The utilisation characteristics of individual QC and RTG cranes are shown in Table 2, provided that the demanded operation continuity of the related equipment is met (regarding comparable Cases 1 and 2). Obviously, this is consistent with the objective function aimed at minimising the turnaround time (vessel servicing time at the berth). Busy state percentage includes two components, which are the operation time and the waiting time. In the case of QCs, the operation time component encompasses picking up a container from the ship and transporting it to the IMV loading position, while the waiting time component is the time needed for the access of the vehicle to its loading position. For the RTG crane, the operation time includes picking up a container from the IMV and its transportation to a specific storage location in a block of storage yard.

Table 2. Utilisation levels of $Q C$ and RTG cranes, following the condition of continual supply of container units at the process input

\begin{tabular}{|c|c|c|c|c|}
\hline \multirow{2}{*}{} & \multicolumn{2}{|c|}{ \% Idle } & \multicolumn{2}{c|}{$\%$ Busy } \\
\cline { 2 - 5 } & Scenario 1 & Scenario 2 & Scenario 1 & Scenario 2 \\
\hline RTG1 & 71,50 & 69,30 & 28,50 & 30,70 \\
\hline
\end{tabular}

\begin{tabular}{|c|c|c|c|c|}
\hline \multirow{2}{*}{} & \multicolumn{2}{|c|}{ \% Idle } & \multicolumn{2}{c|}{ \% Busy } \\
\cline { 2 - 5 } & Scenario 1 & Scenario 2 & Scenario 1 & Scenario 2 \\
\hline RTG2 & 71,43 & 70,70 & 28,57 & 29,30 \\
\hline RTG3 & 70,54 & 71,99 & 29,46 & 28,01 \\
\hline RTG4 & 71,04 & 69,63 & 28,96 & 30,37 \\
\hline RTG5 & 70,57 & 71,43 & 29,43 & 28,57 \\
\hline RTG6 & 70,52 & 72,46 & 29,48 & 27,54 \\
\hline RTG7 & 86,64 & 86,64 & 13,36 & 13,36 \\
\hline QC1 & \multicolumn{3}{|c}{0,32} & \multicolumn{2}{c|}{99,68} \\
\hline QC2 & \multicolumn{3}{|c|}{0,18} & \multicolumn{3}{c}{} \\
\hline
\end{tabular}

Following the established assumptions, the calculated total vessel unloading time (the turnaround time) amounted to 3,358 $\mathrm{min}$, and particularly, for the case of 7 IMVs working in the determined storage area the calculated time was 3,371 min. Thus, the observed time difference for the instances studied was less than $0.5 \%$.

As shown in Table 3 in turn, there are no significant differences concerning the use of QC and RTG cranes for both scenarios and the instance cases using 7 IMVs. As it can be also seen, the limited number of transport resources and strategies adopted for the distribution of containers in the storage yard has no effect on the discussed process output characteristics. The lower utilisation level of RTG cranes is associated with a relatively small number of containers allocated to definite blocks and supported by these container handling resources.

Table 3. Utilisation of RTGs and QCs for the number of IMVs $=7$

\begin{tabular}{|c|c|c|c|c|}
\hline \multirow{2}{*}{} & \multicolumn{2}{|c|}{ Scenario 1 } & \multicolumn{2}{c|}{ Scenario 2 } \\
\cline { 2 - 5 } & \% Idle & \% Busy & \% Idle & \% Busy \\
\hline QC1 & 0,16 & 99,84 & 0,34 & 99,66 \\
\hline RTG1 & 0,2 & 99,8 & 0,18 & 99,82 \\
\hline RTG2 & 71,61 & 28,39 & 69,43 & 30,57 \\
\hline RTG3 & 70,66 & 29,34 & 72,11 & 27,89 \\
\hline RTG4 & 71,15 & 28,85 & 69,75 & 30,25 \\
\hline RTG5 & 70,69 & 29,31 & 71,55 & 28,45 \\
\hline RTG6 & 70,63 & 29,37 & 72,58 & 27,42 \\
\hline RTG7 & 86,69 & 13,31 & 86,69 & 13,31 \\
\hline
\end{tabular}

Table 4. Utilisation statistics of IMVs for analysed cases and Scenario 1

\begin{tabular}{|c|c|c|c|c|c|}
\hline \multicolumn{2}{|c|}{} & \% Idle & \% Demand & \% Transfer & \% Loaded \\
\hline \multirow{3}{*}{ Case 1 } & Min & 78,24 & 3,02 & 2,09 & 14,72 \\
\cline { 2 - 6 } & Max & 79,43 & 3,16 & 3,26 & 15,81 \\
\cline { 2 - 6 } & Mean & 79,00 & 3,08 & 2,63 & 15,29 \\
\cline { 2 - 6 } & Median & 79,07 & 3,08 & 2,64 & 15,31 \\
\hline
\end{tabular}




\begin{tabular}{|c|c|c|c|c|c|}
\hline \multicolumn{2}{|c|}{} & \% Idle & \% Demand & \% Transfer & \% Loaded \\
\hline \multirow{4}{*}{ Case 2 } & Min & 57,87 & 5,94 & 4,85 & 29,67 \\
\cline { 2 - 6 } & Max & 58,70 & 6,42 & 5,67 & 30,81 \\
\cline { 2 - 6 } & Mean & 58,36 & 6,14 & 5,15 & 30,34 \\
\cline { 2 - 6 } & Median & 58,48 & 6,18 & 4,99 & 30,37 \\
\hline \multirow{4}{*}{ Case 3 } & Min & 72,54 & 3,66 & 2,76 & 18,97 \\
\cline { 2 - 6 } & Max & 73,97 & 4,05 & 4,29 & 20,25 \\
\cline { 2 - 6 } & Mean & 73,27 & 3,92 & 3,35 & 19,46 \\
\cline { 2 - 6 } & Median & 73,14 & 3,95 & 3,24 & 19,49 \\
\hline
\end{tabular}

With the commitment of 14 IMVs, about $15 \%$ of the total vehicle working time is spent in the loaded state, regardless of the selected scenario (see Table 4 and Table 5). For Case 3, characterised by the optimum number of IMVs assigned to the transportation task, the time when the available vehicles remain in the loaded state increases by about $5 \%$. Moreover, with 7 IMVs this quoted level is nearly twice as high.

Due to the adopted strategies for vehicle allocation to appropriate blocks, the container loading and unloading operation times at the dissipated structure of possible allocations are almost twice as long, compared to Scenario 2. This is because the individual RTG cranes operating in definite storage blocks have to handle the container units dispatched from both QCs. Such a mode of system operation results in the formation of queues in front of storage blocks, which consequently leads to the increase of the unloading time at the assigned destination of the storage yard.

As mentioned earlier and in order to diminish this adverse effect, the farthest and the nearest load allocation rules to storage blocks have been applied, respectively, for QC1 and QC2.

The shortest queues of vehicles waiting to be unloaded which are observed in instances of Scenario 2 are the result of the assumed allocation strategy that allows the separation of the stream of IMVs into two storage areas, Fig. 6 b. It is also worth mentioning that the demand percentage is at a comparable level for both scenarios, as it can be noted in Table 4 and Table 5.

Table 5. Utilisation statistics of IMVs for analysed cases and Scenario 2

\begin{tabular}{|c|c|c|c|c|c|}
\hline \multicolumn{2}{|c|}{} & \% Idle & \% Demand & \% Transfer & \% Loaded \\
\hline \multirow{4}{*}{ Case 1 } & Min & 80,28 & 3,03 & 0,97 & 14,66 \\
\cline { 2 - 6 } & Max & 81,23 & 3,19 & 1,63 & 15,25 \\
\cline { 2 - 6 } & Mean & 80,69 & 3,08 & 1,16 & 15,07 \\
\cline { 2 - 6 } & Median & 80,68 & 3,06 & 1,08 & 15,10 \\
\hline \multirow{4}{*}{ Case 2 } & Min & 61,45 & 6,07 & 1,80 & 29,55 \\
\cline { 2 - 6 } & Max & 62,18 & 6,20 & 2,45 & 30,19 \\
\cline { 2 - 6 } & Mean & 61,82 & 6,14 & 2,16 & 29,89 \\
\cline { 2 - 6 } & Median & 61,85 & 6,14 & 2,15 & 29,91 \\
\hline
\end{tabular}

\begin{tabular}{|c|c|c|c|c|c|}
\hline \multicolumn{2}{|c|}{} & \% Idle & \% Demand & \% Transfer & \% Loaded \\
\hline \multirow{4}{*}{ Case 3 } & Min & 72,35 & 4,21 & 1,21 & 20,77 \\
\cline { 2 - 6 } & Max & 73,47 & 4,40 & 1,97 & 21,55 \\
\cline { 2 - 6 } & Mean & 72,96 & 4,31 & 1,63 & 21,09 \\
\cline { 2 - 6 } & Median & 73,01 & 4,31 & 1,68 & 21,06 \\
\hline
\end{tabular}

Considerable differences in the lengths of paths travelled by the IMVs, as well as in the numbers of loading cycles executed by QCs can be observed in the performed simulation studies, Table 6. As noted further, in each case under consideration the distance travelled by the transport resources turned out to be directly dependent on the number of IMVs involved into the overall transportation task and indirectly related to the applied allocation strategy.

Table 6. Total distances travelled by IMVs and the number of related loads

\begin{tabular}{|c|c|c|c|c|c|}
\hline \multirow{2}{*}{\multicolumn{2}{|c|}{}} & \multicolumn{2}{c|}{ Scenario 1 } & \multicolumn{2}{c|}{ Scenario 2 } \\
\cline { 2 - 6 } & Loads & Distance & Loads & Distance \\
\hline \multirow{4}{*}{ Case 1 } & Min & 371305 & 149 & 372795 & 148 \\
\cline { 2 - 6 } & Max & 388730 & 152 & 385751 & 152 \\
\cline { 2 - 6 } & Mean & 381073 & 150 & 378033 & 150 \\
\cline { 2 - 6 } & Median & 380901 & 150 & 376831 & 150 \\
\hline \multirow{4}{*}{ Case 2 } & Min & 750682 & 296 & 750540 & 295 \\
\cline { 2 - 6 } & Max & 770988 & 306 & 759642 & 306 \\
\cline { 2 - 6 } & Mean & 762131 & 300 & 756051 & 300 \\
\cline { 2 - 6 } & Median & 762790 & 299 & 758181 & 299 \\
\hline \multirow{5}{*}{ Case 3 } & Min & 473248 & 188 & 521377 & 206 \\
\cline { 2 - 6 } & Max & 495485 & 193 & 539075 & 214 \\
\cline { 2 - 6 } & Mean & 484999 & 191 & 529241 & 210 \\
\cline { 2 - 6 } & Median & 487438 & 191 & 529316 & 211 \\
\hline
\end{tabular}

\section{CONCLUSIONS}

Container terminals represent highly dynamic logistics systems of stochastic nature, where the use of deterministic analysis is insufficient for their proper analysis and quantitative evaluation. Hence a comprehensive simulation study seems to be adequate in this research. The numerical results of the performed simulation runs give insight into their diverse performance characteristics of relevant integrated transportation issues and storage loads in yard blocks (yard storage space) under study (strategies for dispatching / assignment of IMV vehicles), along with their interactions with the handling equipment. As a result, the objective of determining the optimised storage strategy and the utilisation of container transport and handling resources has been provided to a great extent, at the least according to the humble opinion of the authors' team.

Further research will be aimed at the container relocation problem (CRP) with the utilisation of both deterministic and simulation modelling. 
Acknowledgments: Authors would like to thank the management board of DCT Gdansk SA (http://dctgdansk.pl) for valuable tips and advice on the operation of container terminals

\section{BIBLIOGRAPHY}

1. Carlo H.J., Vis I.F.A. and Roodbergen K.J.: Storage yard operations in container terminals: Literature overview, trends, and research directions, European Journal of Operational Research, Vol. 235 (2014), pp. 412-430.

2. Carlo H.J., Vis I.F.A. and Roodbergen K.J.: Transport operations in container terminals: Literature overview, trends, research directions and classification scheme. European Journal of Operational Research, Vol. 236 (2014), pp. 1-13.

3. Forster F. and Bortfeldt A.: A tree search procedure for the container relocation problem. Computers \& Operations Research, Vol. 39 (2012), pp. 299-309.

4. Groover M.P.: Automation, production systems, and computer-integrated manufacturing, Chapter 10, Pearson Prentice - Hall, New Jersey 2008.

5. Günter H.O. and Kim K.H.: Container terminals and terminal operations, OR Spectrum, Vol. 28 (2006), pp. 437-445.

6. Kia M., Shayan E. and Ghotb F.: Investigation of port capacity under a new approach by computer simulation, Computers \& Industrial Engineering, Vol. 42 (2002), pp. 533-540.

7. Murty K.G., Liu J., Wan Y. and Linn R.: A decision support system for operations in container terminal, Decision Support Systems, Vol. 39 (2005), pp. 309-332.

8. Rashidi H. and Tsang E.P.K.: Novel constraints satisfaction models for optimization problems in container terminals. Applied Mathematical Modelling, Vol. 37 (2013), pp. 3601-3634.

9. Steenken D., Voß S. and Stahlbock R.: Container terminal operation and operations research - a classification and literature review, OR Spectrum, Vol. 26 (2004), pp. 3-49.

10. Urbanyi-Popiolek I. and Klopott M.: Container terminals and port city interface - a study of Gdynia and Gdansk ports, Transportation Research Procedia, Vol. 16 (2016), pp. 517-526.

11. Vis I.F.A.: A comparative analysis of storage and retrieval equipment at container terminal, Intl. Journal of Production Economics, Vol. 103 (2006), pp. 680-693.
12. Witnessiver.13. Visual Interactive Simulation Software, User manual, Lanner Group Ltd, Redditch-Worcs, UK 2010-2013.

13. Won S.H. and Kim K.H.: An integrated framework for various operation plans in container terminals. Polish Maritime Research, No. 2 (2009), pp. 51-61.

14. Xin J., Negenborn R.R., Corman F. and Lodewijks G.: Control of interacting machines in automated container terminals using a sequential planning approach for collision avoidance. Transportation Research, Part C, Vol. 60 (2015), pp. 377-396.

15. Yun W.Y. and Choi Y.S.: A simulation model for containerterminal operation analysis using an object-oriented approach, Intl. Journal of Production Economics, Vol. 59 (1999), pp. 221-230.

16. Zhang X., Zeng Q. and Yang Z.: Modeling the mixed storage strategy for quay crane double cycling in container terminals. Transportation Research, Part E, Vol. 94 (2016), pp. 171-187.

17. Zhen L., Xu Z., Wang K. and Ding Y.: Multi-period yard template planning in container terminals. Transportation Research, Part B, Vol. 93 (2016), pp. 700-719.

\section{CONTACT WITH THE AUTHOR}

\author{
Mariusz Deja \\ Michał Dobrzyński \\ Mieczysław S.Siemiątkowski \\ Aleksandra Wiśniewska
}

Gdansk University of Technology,

Mechanical Engineering Faculty, Dept. of Manufacturing

Engineering and Automation

Gdansk

Poland 